Jurnal Interpretasi Hukum | ISSN: 2746-5047

Vol. 2, No. 3-Desember 2021, Hal. 662-666| Tersedia online di

https://www.ejournal.warmadewa.ac.id/index.php/juinhum

DOI: https://doi.org/10.22225/juinhum.2.3.4172.662-666

\title{
KEDUDUKAN ANAK ASTRA (ANAK LUAR KAWIN) DALAM HUKUM KELUARGA DAN KEWARISAN ADAT BALI
}

\author{
I Gede Yudha Rana, I Made Suwitra, Diah Gayatri Sudibya \\ Fakultas Hukum, Universitas Warmadewa, Denpasar-Bali, Indonesia \\ igedeyudharana09@gmail.com, madesuwitra27@gmail.com, diahgayatrisudibya@gmail.com
}

\begin{abstract}
Abstrak
Kehadiran seorang anak dalam keluarga merupakan kebahagiaan sebagai wujud dari buah kasih pasangan suami istri. Memiliki anak merupakan impian semua orang terutam ketika membentuk keluarga baru atau pernikahan sah. Namun hal ini berbanding terbalik dengan anak yang dilahirkan tanpa adanya hubungan perkawinan yang sah sebelumnya sehingga anak tersebut masuk ke dalam golongan anak diluar nikah atau anak astra yang sesuai dengan Pasal 43 Undang-undang Nomor 1 Tahun 1974 tentang Perkawinan. Anak diluar nikah ini kadang menjadi masalah dalam keluarga karena tidak semua ayah tiri menerima keberadaan mereka. Penelitian ini bertujuan mengungkapkan posisi anak dalam keluarga kewarisan adat di Desa Malet Kutamesir dan menganalisis perlindungan terhadap anak astra dalam hukum keluarga dan kewarisan di Desa Adat Malet Kutamesir. Penelitian ini menggunakan tipe penelitian hukum empiris dengan pendekatan konsep (conceptual approach). Data yang digunakan yaitu data primer dan sekunder yang diperoleh melalui teknik wawancara serta teknik studi pustaka serta dianalisis secara kualitatif dan interpretasi hukum dengan penyajian akhir secara deskriptif. Hasil penelitian ini mengungkapkan bahwa anak astra hanya memiliki kedudukan hukum dalam mewarisi harta ibunya saja serta anak astra berhak mendapatkan perlindungan dari apapun yang terjadi di sekitar kehidupannya baik itu di rumah atau di luar rumah.
\end{abstract}

Kata Kunci: Anak Astra, Hak Waris, Perlindungan Hukum

\begin{abstract}
The presence of a child in the family is happiness as a manifestation of the fruit of a husband and wife's love. Having children is everyone's dream, especially when starting a new family or legal marriage. However, this is inversely proportional to children who are born without a previous le gal marriage relationship so that the child is included in the class of children outside marriage or Astra children in accordance with Article 43 of Law Number 1 of 1974 concerning Marriage. This child out of wedlock sometimes becomes a problem in the family because not all stepfathers accept their existence. This study aims to reveal the position of children in traditional inheritance families in the Malet Village of Kutamesir and analyze the protection of Astra children in family law and inheritance in the Indigenous Village of Malet Kutamesir. This study uses an empirical legal research type with a conceptual approach. The data used are primary and secondary data obtained through interview techniques and literature study techniques and analyzed qualitatively and legal interpretation with a descriptive final presentation. The results of this study reveal that an astra child only has a legal position in inheriting his mother's property and an astra child has the right to get protection from whatever happens around his life, be it at home or outside the home.
\end{abstract}

Keywords: Astra Children, Inheritance Rights, Legal Protection

\section{PENDAHULUAN}

Persoalan menyangkut adat di Bali diselesaikan melalui penerapan aturan (awig-awig) desa adat yang berlaku. Perkumpulan yang paling disetujui untuk menentukan standar masalah yang muncul adalah Prajuru desa adat untuk situasi ini adalah Bendesa Adat (Kepala Adat) bersama Prajuru lainnya melalui pakraman (Sukerti \& Ariani, 2018). Bagi masyarakat adat Bali, keberadaan awig-awig dikenal sebagai aturan yang menjadi pedoman bagi desa-desa adat dalam menyelesaikan permasalahan di pemerintahannya. Awig-awig adalah aturan yang dibuat baik secara tersusun atau tidak tertulis yang berlaku untuk semua jaringan di setiap desa adat di Bali (Surpha, 2004). Maka di 
dalam aturan perkawinan, secara eksplisit awig-awig memuat isi terkait Bab Sukerta Tata Pawongan yang mengatur setiap aspek-aspek hukum keluarga baik itu indik pawiwahan (perihal perkawinan), indik nyapian (perihal perceraian), indik sentana (perihal anak keturunan), serta indik warisan (perihal pewarisan).

Pada bagian indik pawiwahan, ia mengarahkan tata cara perkawinan (pemargin pawiwahan), syarat-syarat perkawinan (pidabdab sang pacang mawiwaha), dan tata cara perkawinan (pawiwahan pemargin). Secara yuridis, sebagaimana ditunjukkan dalam Undang-undang Nomor 1 Tahun 1974 tentang Perkawinan, tidak mengatur pedoman adat untuk menyelesaikan hubungan. Karena pada dasarnya perkawinan adalah suatu perjanjian adat dan mempunyai akibat-akibat yang sah secara lokal yang bersangkutan, terutama setelah siklus perkawinan terjadi, maka hak-hak dan kewajibankewajiban wali, termasuk kerabat dan anggota keluarga, sebagaimana ditunjukkan oleh hukum adat terdekat muncul (Sembiring, 2016).

Alasan menikah lebih eksplisit antara lain untuk melahirkan anak atau memiliki keturunan. Kehadiran anak hasil perkawinan merupakan kepuasan dan kemajuan bagi wali dan keluarganya, meskipun ada yang tidak menyangka bahwa pengenalan anak membuat wali memiliki hak dan komitmen untuk menjamin hak-hak dasar anak, misalnya memenuhi pendidikan anak. Perkembangan dan kemajuan anak, pemberian pelatihan dan kesejahteraan, serta pemberian kasih sayang. Namun pada umumnya, tidak semua menganggap kehadiran seorang anak dalam sebuah keluarga merupakan suatu kebahagiaan jika sang anak telah dilahirkan ke dunia sebelum nikah, anak tersebut juga disebut sakit. Seorang anak muda dapat dianggap sebagai anak sejati yang memiliki hubungan dengan ayahnya jika dia dilahirkan ke dunia dari pernikahan yang sah. Sebaliknya, bila anak yang lahir dari hasil perkawinan yang tidak sah maka anak tersebut tidak memiliki hubungan perdata dengan ayahnya serta tidak boleh mewarisi harta yang dimiliki oleh ayahnya. Sehingga anak seperti ini sering disebut anak zina atau anak di luar dari perkawinan sah sesuai dengan Pasal 43 Undang-undang Nomor 1 Tahun 1974 tentang Perkawinan menyatakan bahwa anak yang dilahirkan dari hasil perkawinan yang tidak sah hanya boleh mewarisi harta ibunya serta tidak memiliki hubungan perdata dengan ayahnya.

Tanpa kehadiran ayah, anak-anak hanya memiliki hubungan keluarga dengan ibu dan keluarga ibu, namun tidak mengecualikan hak waris kepada keluarga ibu. Anak itu hanya memenuhi syarat untuk warisan yang diklaim oleh ibu (Soeripto, 1973). Hal ini masih bisa diterapkan untuk seorang anak dengan hanya satu orang tua hadir untuk diakui di wilayah hukum standar Bali untuk alasan tertentu. Salah satunya melegitimasi anak-anak dengan hanya satu orang tua yang hadir dengan cara mencicil secara konvensional atau mengadakan upacara adat agar anak-anak di luar nikah dapat diakui dan tinggal secara lokal dan berhubungan dengan ibunya (Dornikus, 2015); (Hadikusuma, 2003). Seperti di Bali, penting untuk memeriksa bagaimana kedudukan yang diberikan kepada anak yang disalahpahami, jika mereka adalah penerima manfaat. Atas dasar ini, sangat lazim bahwa anakanak muda diberikan jaminan oleh negara (Witanto, 2021). Karena kedudukan anak diluar nikah masi menjadi masalah serius dalam keluarga maka penelitian ini mengkaji ulang kedudukan anak astra dalam hukum kekeluargaan dan kewarisan adat bali, serta mengungkapkan perlindungan anak yang hadir diluar perkawinan yang sah.

\section{METODE PENELITIAN}

Penelitian ini menggunakan tipe penelitian hukum empiris yaitu penelitian yang mengkaji dan menganalisa bekerjanya hukum dalam masyarakat (low in action) data utama yang digunakan adalah data yang bersumber dari lapangan (Muhammad, 2008). Pendekatan yang digunakan adalah pendekatan konsep (conceptual approach) yang akan dipergunakan untuk menganalisis konsepkonsep pengaturan mengenai kedudukan hukum anak astra. Pengumpulan bahan hukum primer dan sekunder dilaksanakan melalui studi kepustakaan dan wawancara. Peneliti membaca dan menelaah peraturan Perundang-undangan melalui teknik wawancara serta teknik studi data hukum (Soekanto, 1986). Setelah data penelitian terkumpul, maka peneliti mengolah dan menganalisis menggunakan teknik analisis bahan hukum secara kualitatif dan interpretasi hukum serta disajikan secara deskriptif analisis (Marzuki, 2016) 


\section{HASIL DAN PEMBAHASAN}

\section{Kedudukan Anak Astra dalam Hukum Keluarga Kewarisan Adat di Desa Malet Kutamesir}

Berdasarkan hukum adat Bali, anak yang lahir diluar perkawinan yang sah hanya dapat mewaris terhadap harta peninggalan ibunya dan dari keluarga ibunya, begitu pula bila anak itu meninggal dunia dan meninggalkan warisan maka harta peninggalan tersebut juga akan diwariskan kepada ibunya atau keluarga ibunya. Anak yang lahir dari perkawinan yang sah maka disebut pewaris, tapi berbeda dengan perkawinan antara seorang wanita berpangkat Sudra dan seorang pria dari kelompok Tri Wangsa diketahui bahwa wanita tersebut sedang hamil dan telah memasuki masa kehamilan lebih dari lima bulan, pernikahan tidak substansial. Perkawinan baru dapat terjadi setelah anak dalam perut wanita dikandung telah lahir, namun anak yang dikandung tidak dapat dilegitimasi sebagai anak yang sah (astra astra). (wawancara I Wayan Rana sebagai dengan Bendesa Adat, tanggal 28 juni2021).

Anak Astra tidak memiliki hubungan yang sama dengan ayahnya, menyiratkan bahwa dia bukan ahli waris ayahnya meskipun dia dinyatakan sebagai anak oleh ayahnya. Bagaimanapun, dengan alasan bahwa untuk situasi ini dia tidak diizinkan untuk diakui sebagai anak muda sejati, posisinya bukan sebagai ahli waris ayah kandungnya, dia mungkin akan diatur dengan sengaja oleh wali alaminya, sebagai terjadi di Adat Kutamesir Malet, anak Astra berjenis kelamin laki-laki dalam hidupnya akan dibiayai hingga dewasa oleh keluarga ayah kandungnya dan setelah menikah diberi tempat tinggal sebagai pekarangan di sekitar wilayah Adat Kutamesir atau rumah keluarga yang lebih jauh dari ayah kandungnya (Atmasasmita, 1997).

Menurut Bendesa Adat Malet Kutamesir, pola keluarga standar Malet Kutamesir adalah patrilineal, yaitu mengikuti garis ayah (laki-laki), namun tidak hanya melihat hubungan dari sisi ayah (laki-laki), namun selain itu hubungan kekeluargaan dari pihak ibu. Sesuai hukum standar di Kota Adat Malet Kutamesir, itu adalah hak yang diperoleh seseorang secara darah atau keturunan. Meskipun demikian, hak warisan harus melalui hubungan darah atau kerabat yang dibawa ke dunia dari hubungan yang sah. Perkawinan yang halal akan melahirkan keturunan yang halal (anak-anak). Hubungan yang sah antara seorang anak dengan orang tuanya sangat tergantung pada keabsahan perkawinan orang tuanya. Jadi kerangka hubungan Patrilineal ini menganggap hubungan keluarga melalui garis laki-laki adil, sepanjang garis ini melahirkan setiap individu dari daerah setempat hanya dengan memperhatikan anggota keluarga ayah mereka dalam batas-batas hubungan keluarga, yang disebut Purusa. Kemudian, pada saat itu bagi kerabat lainnya, anak dengan hanya satu orang tua hadir adalah orang lain, oleh karena itu ia tidak memiliki hak istimewa untuk memperoleh dari warisan keluarga ayah atau ibu yang mengingatnya.

\section{Perlindungan Terhadap Anak Astra dalam Hukum Keluarga dan Kewarisan di Desa Adat Malet Kutamesir}

Berbicara tentang perlindungan hukum yang sah dari anak astra dilakukan dengan tujuan menjaga, merawat serta memelihara agar anak tersebut tetap memperoleh hak keamanannya. Seperti dalam Undang-undang Nomor 23 Tahun 2004 tentang Penghapusan Kekerasan dalam rumah tangga, dalam hal ini anak dikatakan sebagai seorang yang lahir ke dunia dari hubungan perkawinan yang sah mengikat antara seorang wanita dan seorang pria tanpa mengabaikan seseorang yang dilahirkan ke dunia oleh seorang laki-laki, meskipun fakta bahwa mereka belum pernah menikah dan wajib dianggap sebagai anak. Anak juga merupakan cikal bakal pengenalan zaman lain yang merupakan sumber daya negara, yang nantinya akan membawa nasib negara kedepannya.

Perlindungan anak adalah tugas yang wajib dijalankan pemerintah untuk memberikan keadaan yang mampu untuk diterapkan dalam menjamin hak serta komitmen bagi anak-anak dengan cara altruistik yang positif. Untuk keadaan ini anak dilindungi oleh Undang-undang. Sesuai UUNomor 23 Tahun 2002 tentang Perlindungan Anak. Dari hasil wawancara yang dilakukan pada tanggal 10 juli 2021 dengan Bendesa Adat Dari Desa Adat Malet Kutamesir yaitu I Wayan Rana anak seharusnya dilindungi dari gangguan apapun demi terhindar dari tekanan mental baik di rumah maupun di lingkungan sekitar. Desa Adat Malet Kutamesir sudah melindungi hal-hal yang kemungkinan menimpa anak tersebut melalui penerapan awig-awig agar bila terjadi pelanggaran mampu diproses secara hukum. Tapi hal tersebut masih berupa wacana dari Desa Adat Malet Kutamesir, sehingga dalam hal ini sebagai pihak keluarga wajib melindungi terlebih dahulu sebelum diberlakukan awig- 
awig dari Desa Adat Kutamesir tersebut. Dengan langkah ini anak tersebut masih bisa menikmati kepastian hak maupun hukum agar terhindar dari tekanan mental.

Adanya perlindungan terhadap anak astra di Desa Adat Malet Kutamesir berdasarkan wawancara dengan Bendesa pada tanggal 10 Juli 2021 menyatakan:

1. Perlindungan oleh keluarga terkait dengan perlindungan anak astra sisi keluarga

a. Menurut hukum Adat Malet Kutamesir setiap keluarga wajib mengetahui wajib mengetahui dan mempunyai silsilah keluarga.

b. Berdasarkan silsilah tersebut di atas maka keluarga akan mengetahui hak dan kewajiban keluarga untuk melindungi anak astra terkait dengan kepentingan atau kebutuhan anak astra di masyarakat.

2. Perlindungan oleh Adat Malet Kutamesir, yang meliputi perlindungan dari sisi sekala dan niskala

a. Dari sisi Sekala

1) Prajuru Desa Adat Malet Kutamesir selalu memberikan pelayanan terhadap anak astra karena anak astra juga bagian dari warga Desa Adat dan sebagai negara yang harus dilindungi.

2) Anak astra juga harus dijaga dari sisi hukum sosial di masyarakat dan tidak diijinkan atau tidak diperbolehkan untuk membeda-bedakan dengan anak yang lain di Desa Adat Malet Kutamesir dalam kehidupan sehari-hari.

b. Dari sisi Niskala

1) Desa adat selalu tidak membeda-bedakan anak astra dengan anak masyarakat pada umumnya untuk melaksanakan kegiatan keagamaan menurut keyakinan yang dianut.

2) Apabila anak astra melaksanakan kegiatan keagamaan yang terkait dengan adat akan selalu diakui dan disaksikan secara sekala dan niskala melalui tri upasaksi.

Desa Adat Malet Kutamesir merupakan tempat perlindungan warga bali. Awig-awig dan pararem berhasil dalam menata kehidupan warga bali, hingga awig-awig yang telah menjadi aturan desa lebih diwaspadai oleh masyarakat. Dikarenakan awig-awig mampu memberikan dampak lebih bagi pelanggar nya secara langsung. Maka dari itu perlindungan terhadap anak sangat dijamin dengan adanya awig-awig yang berlaku di Desa Adat Kutamesir, apalagi awig-awig ini telah direncanakan untuk diperbaharui agar perlindungan yang didapatkan lebih dipertegas.

\section{SIMPULAN DAN SARAN}

\section{Simpulan}

Dari hasil pembahasan penelitian tersebut di atas, dapat disimpulkan bahwa kedudukan anak astra dalam hukum keluarga dan Kewarisan di Desa Adat Malet kutamesir yaitu anak astra merupakan ahli waris dari Ibunya saja, tidak memiliki hubungan pribadi dengan bapaknya, jika dihubungkan dengan harta warisan yang berupa hak-hak dan kewajiban yang beralih penguasaan atau kepemilikannya setelah Ibu anak meninggal dunia, hanya anak astra berhak mewaris harta warisan ibunya saja termasuk harta asal, dan harta pusaka ibunya. Anak astra tidak mewarisi dari ayah biologisnya namun pada umumnya anak astra diberikan harta jiwa dana dan kebutuhan oleh ayah biologisnya sebagai tanggung jawab atas pengakuan orang tua kepada anaknya. Perlindungan anak astra dalam hukum keluarga dan kewarisan di desa Adat Malet Kutamesir Anak astra seharusnya dilindungi dari gangguan apapun demi terhindar dari tekanan mental baik di rumah maupun di lingkungan sekitar. Adanya perlindungan terhadap anak astra di Desa Adat Malet Kutamesir yang meliputi perlindungan oleh keluarga dan perlindungan desa adat malet kutamesir yang meliputi perlindungan dari sisi sekala dan niskala.

\section{Saran}

Berkaitan simpulan penelitian di atas, adapun saran yang disampaikan oleh peneliti adalah diharapkan bagi keluarga anak astra tetap terlindungi dari sisi hukum adat, keluarga, dan hukum sosial. Kepastian Terhadap anak astra tidak dibatasi hak-hak untuk hidup dan hak warisan dikarenakan anak astra adalah bagian dari keluarga ibu yang melahirkan agar keluarga selalu menjaga dan bertanggung jawab terkait masa depan anak astra khususnya di bidang pendidikan, kesehatan, dan keamanan. Kepada desa adat diharapkan agar menyikapi anak astra di masyarakat selalu mengedepankan hak asasi manusia dan memperbarui awig-awig berkaitan dengan keberadaan anak astra sehingga menjadi jelas 
keberadaan anak astra di desa Malet Kutamesir di hadapan Keluarga Ibunya di masyarakat malet kutamesir.

\section{DAFTAR PUSTAKA}

Atmasasmita, R. (1997). Peradilan Anak di Indonesia. Mandar Maju: Bandung.

Dornikus, R. (2015). Hukum Perkawinan dan Waris Adat di Indonesia. Sura Baya: Laksbang Presindo.

Hadikusuma, H. (2003). Pengantar Ilmu Hukum Adat Indonesia. Mandar Maju.

Marzuki, P. M. (2016). “Penelitian Hukum.”Jakarta: Kencana.

Muhammad, A. (2008). Hukum Pengangkutan Niaga. PT. Citra Aditya Bakti.

Sembiring, R. (2016). Hukum Keluarga Harta-Harta Benda dalam Perkawinan. Raja Grafindo Persada.

Soekanto, S. (1986). Pengantar Penelitian Hukum. UI press: Jakarta.

Soeripto. (1973). Beberapa Bab Tentang Hukum Adat Waris Bali. Jember: UNEJ.

Sukerti, N. N., \& Ariani, I. G. A. A. (2018). Budaya Hukum Masyarakat Adat Bali Terhadap Eksistensi Perkawinan Beda Wangsa. Jurnal Magister Hukum Udayana (Udayana Master Law Journal), 7(4), 516-528.

Surpha, I. W. (2004). Eksistensi Desa Adat dan Dinas di Bali. Pustaka Bali Post.

Witanto, D. Y. (2021). Hukum Keluarga Hak dan Kedudukan Anak Luar Kawin Pasca Keluarnya Putusan MK Tentang Uji Materiil UU Perkawinan. Prestasi Pustaka Publisher: Jakarta. 